\title{
Anesthetic effects of isoflurane and the molecular mechanism underlying isoflurane-inhibited aggressiveness of hepatic carcinoma
}

\author{
JING HU, JINGLI HU, HONGMEI JIAO and QINGGUO LI \\ Department of Anesthesiology, Linyi Cancer Hospital, Linyi, Shandong 276001, P.R. China
}

Received September 29, 2016; Accepted November 2, 2017

DOI: $10.3892 / \mathrm{mmr} .2018 .8945$

\begin{abstract}
Anesthesia is produced by drugs or other methods, and refers to the attenuation of pain via reversible suppression of neuronal transmission in the central and peripheral nervous systems, during surgery. Clinical investigations have indicated that the anesthetic action of isoflurane is efficient to alleviate pain during tumor resection clinical trials. In addition, it has been reported that isoflurane can induce caspase-3 activation and is associated with apoptosis of tumor cells. The present study investigated the anesthetic effects and molecular mechanisms underlying isoflurane-induced apoptosis in patients with hepatic carcinoma. Furthermore, the pain of patients with hepatic carcinoma was evaluated during the perioperative period according to the pain index. The apoptotic rate of hepatic carcinoma cells was analyzed in tumor tissues using TUNEL assay. The expression levels of apoptosis-associated proteins were detected in liver cancer cells following anesthesia in patients. Phosphoinositide 3-kinase/protein kinase B (PI3K/AKT) and nuclear factor (NF)- $\mathrm{KB}$ signaling pathways were also analyzed in liver cancer cells following treatment with isoflurane. The results demonstrated that isoflurane inhibited growth and decreased viability of liver cancer cells in vitro and in vivo. In addition, the apoptotic rate was increased in cells obtained from isoflurane-treated patients. The results also demonstrated that isoflurane upregulated the expression levels of proapoptotic genes and downregulated anti-apoptotic mRNA expression. In addition, a molecular mechanism analysis indicated that isoflurane inhibited PI3K and AKT expression in liver cancer cells. Isoflurane also induced caspase-3 activation in liver cancer cells. Furthermore, isoflurane treatment attenuated NF- $\mathrm{kB}$ activity and inhibited migration and invasion of liver cancer cells. In conclusion,
\end{abstract}

Correspondence to: Professor Qingguo Li, Department of Anesthesiology, Linyi Cancer Hospital, 6 East Lingyuan Street, Linyi, Shandong 276001, P.R. China

E-mail: liqingguoprof@yeah.net

Key words: isoflurane, anesthesia, hepatic carcinoma, phosphoinositide 3-kinase/protein kinase $\mathrm{B}$, nuclear factor- $\kappa \mathrm{B}$, apoptosis these findings indicated that isoflurane treatment efficiently attenuated surgical pain and inhibited tumor aggressiveness via regulation of NF- $\mathrm{KB}$ activity and the PI3K/AKT signaling pathway, thus suggesting that isoflurane is an efficient anesthetic drug that induces pain remission and promotes apoptosis of liver cancer cells.

\section{Introduction}

Hepatic carcinoma is associated with high levels of morbidity and mortality (1). In addition, hepatocellular carcinoma is the second most common type of cancer, the incidence of which is increasing worldwide, which accounts for $>90 \%$ of primary liver cancer cases $(2,3)$. At present, the common clinical therapeutic strategies for hepatic carcinoma include surgery, chemotherapy and radiotherapy; however, these treatments present only modest efficacy and often induce side effects in patients $(4,5)$. In addition, the efficacy of these conventional therapeutic strategies remain limited, particularly for patients with late stage, advanced hepatic carcinoma (6). Although the efficacy of aggressive surgery is limited for patients with cancer, tumor resection is the most common clinical strategy used to treat patients with hepatic carcinoma. Therefore, various anesthetics have been developed and applied in tumor resection to attenuate surgical pain for patients with hepatic carcinoma during the perioperative period. Additional functions of anesthetics have also been reported and further analyzed in hepatic carcinoma cells and tissues.

Isoflurane is a volatile general anesthetic that can be applied for the induction and maintenance of general anesthesia, in order to abolish the behavioral responsiveness of patients during tumor resection (7). It has previously been reported that pretreatment with isoflurane influences the cytokine response to cancer surgery during the perioperative period (8). In addition, research has indicated that the effects of isoflurane may activate the caspase-induced apoptotic signaling pathway; this cellular response is consistent with the neuropathogenesis of senile dementia (9). In addition, Liu revealed that isoflurane can increase serum levels of interleukin (IL)-8 and IL-10 in patients with cancer (10). Furthermore, emulsified isoflurane treatment can inhibit the cell cycle and respiration of human bronchial epithelial 16HBE cells in a p53-independent manner (11). The anesthetic efficacy of isoflurane has also been investigated in patients undergoing craniotomy for primary brain tumor 
excision (12). These data suggest that is of lurane may regulate various signaling pathway in tumor cells during the perioperative period. Therefore, it may be hypothesized that isoflurane inhibits hepatic carcinoma growth and aggressiveness, and promotes apoptosis via the phosphoinositide 3-kinase/protein kinase B (PI3K/AKT)-mediated nuclear factor (NF)- $\kappa \mathrm{B}$ signal pathway.

Oncogenic Ras signaling, resulting in activation of the PI3K/AKT pathway, has been analyzed during tumor maintenance (13). The PI3K/AKT signaling pathway serves an essential role in cell growth, proliferation and survival under physiological conditions (14). A previous study suggested that inhibition of PI3K/AKT signaling could induce apoptosis, and impair mammary tumor outgrowth and metastasis (15). In addition, isoflurane-induced neuroapoptosis via the PI3K/AKT pathway has been investigated in vivo and the expression of PI3K and AKT has been reported to affect neuroapoptosis (16). Furthermore, the PI3K/AKT-induced NF- $\kappa$ B signaling pathway is associated with tumor angiogenesis and provides a novel insight into the mechanisms underlying cancer cell growth and aggressiveness (17). In addition, Miao and Zhao indicated that inhibition of the PI3K/AKT/NF- $\mathrm{B}$ signaling pathway could suppress tumor invasion in follicular thyroid carcinoma (18). These reports suggest that the PI3K/AKT-mediated NF- $\kappa \mathrm{B}$ signal pathway may serve an essential role in the initiation and progression of carcinoma growth and aggressiveness. Therefore, the present study investigated the expression and activity of the PI3K/AKT-mediated NF- $\kappa \mathrm{B}$ signaling pathway in hepatic carcinoma cells following treatment with isoflurane.

In the present study, the anesthetic and cellular effects of isoflurane on hepatic carcinoma cell biology were investigated, in order to better understand the mechanisms underlying isoflurane-mediated tumor suppression in patients with hepatic carcinoma. The present study also evaluated the molecular mechanism underlying isoflurane-induced apoptosis and tumor therapy for patients with hepatic carcinoma.

\section{Materials and methods}

Ethics statement. The present study was directed according to the Guide for the Care and Use of Clinical Investigation of Anesthesiology of Linyi Cancer Hospital (Linyi, China). The present study was approved by the ethics committee of Linyi Cancer Hospital. All patients provided written informed consent.

Patients. A total of 10 patients with hepatic carcinoma were recruited in Linyi Cancer Hospital between June 2013 and May 2014. The mean age was 46.7 years old (range, 38.5-62.5 years old). Patients with a history of cancer were excluded from this study. None of the patients had received anti-cancer treatments before tumorectomy. Patients were treated with total intravenous anesthesia isoflurane $(n=5$, $10 \mathrm{mg} / \mathrm{kg})$ or propofol $(\mathrm{n}=5,2 \mathrm{mg} / \mathrm{kg})$.

Pharmacodynamics analysis. Serum concentrations of isoflurane and Cmax concentrations of isoflurane were analyzed in patients with hepatic carcinoma after anesthesia. Serum concentrations of isoflurane were recorded at 0-120 min (15 min interval). Cmax concentrations of isoflurane were evaluated at $0-25 \mathrm{mg} / \mathrm{kg}$ (5 mg/kg interval). Concentrations of isoflurane (Cmax) were determined by High Performance Liquid Chromatography as described previously (19).

Cell culture. Hepatic carcinoma cells were isolated from patients with hepatic carcinoma and were cultured in Dulbecco's modified Eagle's medium (DMEM; Sigma-Aldrich; Merck KGaA, Darmstadt, Germany) supplemented with 5\% fetal bovine serum (Gibco; Thermo Fisher Scientific, Inc., Waltham, MA, USA). Tumor cells were cultured at $37^{\circ} \mathrm{C}$ in a humidified atmosphere containing $5 \% \mathrm{CO}_{2}$. Cells were treated with isoflurane ( $2 \mathrm{mg} / \mathrm{ml})$ and/or PI3K inhibitor $(2 \mathrm{mg} / \mathrm{ml})$ for $12 \mathrm{~h}$ at $37^{\circ} \mathrm{C}$ for further analysis.

MTT assay. Hepatic carcinoma cells $\left(1 \times 10^{3}\right.$ cells/well) were incubated in 96 -well plates for $72 \mathrm{~h}$ at $37^{\circ} \mathrm{C}$ in triplicate. Cells were then treated with isoflurane $(2 \mathrm{mg} / \mathrm{ml})$ or isoflurane $\left(2 \mathrm{mg} / \mathrm{ml}\right.$ ) for $48 \mathrm{~h}$ at $37^{\circ} \mathrm{C}$. Subsequently, $20 \mu \mathrm{l} \mathrm{MTT}$ solution $(5 \mathrm{mg} / \mathrm{ml})$ was added to the cells and the plates were incubated for $2 \mathrm{~h}$ at $37^{\circ} \mathrm{C}$. The medium was then removed and $100 \mu \mathrm{l}$ dimethyl sulfoxide was added to the wells to solubilize the crystals. Absorbance was measured using an ELISA reader at a wavelength of $450 \mathrm{~nm}$.

Cell viability assay. Hepatic carcinoma cells ( $1 \times 10^{3}$ cells/well) were seeded in 96-well plates and cultured for $12 \mathrm{~h}$ at $37^{\circ} \mathrm{C}$. Cells were then treated with isoflurane $(2 \mathrm{mg} / \mathrm{ml})$ or isoflurane $(2 \mathrm{mg} / \mathrm{ml})$ for $48 \mathrm{~h}$ at $37^{\circ} \mathrm{C}$. The CCK- 8 detection kit (Sigma-Aldrich; Merck KGaA) was used to measure cell viability according to the manufacturer's instructions.

RNA isolation and reverse transcription-quantitative polymerase chain reaction $(R T-q P C R)$. Total RNA was extracted from hepatic carcinoma cells using RNAeasy Mini kit (Qiagen, Inc., Gaithersburg, MD, USA). mRNA expression levels were measured by RT-qPCR using an RT-qPCR kit (A15300; Thermo Fisher Scientific, Inc.). All the forward and reverse primers were synthesized by Invitrogen (Thermo Fisher Scientific, Inc., Table I). Thermocycling conditions included 45 amplification cycles, denaturation at $95^{\circ} \mathrm{C}$ for $45 \mathrm{sec}$, primer annealing at $62.5^{\circ} \mathrm{C}$ for $30 \mathrm{sec}$ with touchdown to $54^{\circ} \mathrm{C}$ for $45 \mathrm{sec}$ and applicant extension at $72^{\circ} \mathrm{C}$ for $60 \mathrm{sec}$. The relative mRNA expression levels of B-cell lymphoma 2 (Bcl-2), Bcl-2-associated X protein (Bax), caspase-3 and caspase- 8 were calculated according to the $2^{-\Delta \Delta \mathrm{Cq}}$ method (20). The results were analyzed in triplicate according to the $2^{-\Delta \Delta \mathrm{Cq}}$ method, and were normalized to $\beta$-actin.

Western blotanalysis. Hepatic carcinoma cells $\left(1 \times 10^{5}\right.$ cells/well $)$ were seeded in 6 -well plates and cultured for $12 \mathrm{~h}$ at $37^{\circ} \mathrm{C}$. Cells were then treated with isoflurane $(2 \mathrm{mg} / \mathrm{ml})$ or isoflurane $\left(2 \mathrm{mg} / \mathrm{ml}\right.$ ) for $48 \mathrm{~h}$ at $37^{\circ} \mathrm{C}$. Hepatic carcinoma cells isolated from patients with hepatic cancer were homogenized in lysis buffer containing protease inhibitor (P3480; Sigma-Aldrich; Merck $\mathrm{KGaA}$ ), and were centrifuged at $8,000 \mathrm{x} \mathrm{g}$ for $10 \mathrm{~min}$ at $4^{\circ} \mathrm{C}$. The supernatant was used to analyze the expression of target proteins. Protein concentration was measured by a BCA protein assay kit (Thermo Fisher Scientific, Inc.). Protein samples $(20 \mu \mathrm{g})$ were resolved by $15 \%$ SDS-PAGE and then transferred onto polyvinylidene fluoride membranes 
Table I. Sequences of primers used in the present study.

Sequence

\begin{tabular}{lll}
\cline { 2 - 3 } Gene name & \multicolumn{1}{c}{ Forward } & \multicolumn{1}{c}{ Reverse } \\
\hline Bax & 5'-TGGCAGCTGACATGTTTTCTGAC-3' & 5'-TCACCCAACCACCCTGGTCTT-3' \\
Bcl-2 & 5'-CGTCATAACTAAAGACACCCC-3' & 5'-TTCATCTCCAGTATCCGACT-3' \\
Caspase-3 & 5'-ATGGAGAACAACAAAACCTCAGT-3' & 5'-TTGCTCCCATGTATGGTCTTTAC-3' \\
Caspase-8 & 5'-CACTAGAAAGGAGGAGATGGAAAG-3' & 5'-CTATCCTGTTCTCTTGGAGAGTCC-3' \\
$\beta$-actin & 5'-ACGGTCAGGTCATCACTATCG-3' & 5'-GGCATAGAGGTCTTTACGGATG-3' \\
\hline
\end{tabular}

Bax, Bcl-2-associated X protein; Bcl-2, B cell lymphoma-2.

(EMD Millipore, Billerica, MA, USA). For western blotting, primary mouse anti-human antibodies against p65 (ab16502; 1:2,000), PI3K and (ab40776; 1:2,000), AKT (ab8805; 1:1,000), tumor necrosis factor (TNF)- $\alpha$ (ab6671; 1:2,000), IL-2 (cat. no. ab92381; 1:2,000), IkB kinase (IKK)- $\beta$ (ab7547; 1:2,000), NF-кB inhibitor $\alpha(\mathrm{I} \kappa \mathrm{B} \alpha$; ab133478; $1: 2,000)$, pAKT $(a b 38449 ; 1: 12,000)$ and $\beta$-actin $(a b 8827$; 1:2,000; all from Abcam, Cambridge, UK) were added to the membranes after blocking with 5\% skimmed milk for $2 \mathrm{~h}$ at $37^{\circ} \mathrm{C}$. Following washing three times with PBS, membranes were incubated with secondary rabbit anti-mouse antibodies (PV-6001; 1:2,000; OriGene Technologies, Inc., Beijing, China) for $2 \mathrm{~h}$ at $37^{\circ} \mathrm{C}$, in order to detect target proteins. The results were visualized using a chemiluminescence detection system (GE Healthcare Life Sciences, Little Chalfont, UK) according to the manufacturer's protocol.

Cells migration and invasion assays. Hepatic carcinoma cells were cultured in DMEM for $48 \mathrm{~h}$ at $37^{\circ} \mathrm{C}$. Cells were suspended at a density of $1 \times 10^{5}$ in $500 \mu \mathrm{l}$ serum-free DMEM. Hepatic carcinoma cells were then plated in the upper chambers of a chamber inserts (BD Biosciences, San Jose, CA, USA) with only DMEM and DMEM with 5\% FBS in the lower chambers according to the manufacturer's protocol. In addition, hepatic carcinoma cells $\left(1 \times 10^{6}\right)$ were incubated with isoflurane $(2 \mathrm{mg} / \mathrm{kg})$ or PBS $(2 \mathrm{mg} / \mathrm{kg})$ for $72 \mathrm{~h}$ at $37^{\circ} \mathrm{C}$ in a Matrigel-coated membrane (BD Biosciences). The cells were fixed and stained for $30 \mathrm{~min}$ in a $0.1 \%$ crystal violet solution in PBS. The tumor cell invasion and migration was counted in at least three random fields/membrane, by light microscopy (Olympus Corporation, Tokyo, Japan) at magnification, x40.

Pain assessment. To determine the efficacy of isoflurane for postoperative pain remission in patients (the same patients used for cell collection) with hepatic carcinoma who had undergone tumor resection, general appearance parameter (GAP) scores were used to calculate the pain score $4 \mathrm{~h}$ post operation. GAP scoring was conducted according to previously published parameters regarding posture, activity and breathing pattern (21).

Apoptosis assay. TUNEL assays were used to analyze the apoptotic rate of hepatic carcinoma cells from patients with hepatic carcinoma who had undergone tumor resection following pretreatment with isoflurane. The TUNEL assay was performed according to a previous study (22).

$N F-\kappa B$ activity. Hepatic carcinoma cells were cultured and treated with isoflurane $(2 \mathrm{mg} / \mathrm{kg})$ or PBS $(2 \mathrm{mg} / \mathrm{kg})$ for $12 \mathrm{~h}$ at $37^{\circ} \mathrm{C}$. Subsequently, NF- $\kappa B$ activity was analyzed according a method described in a previous study (23).

Statistical analysis. All data are presented as the mean \pm standard error of the mean. Unpaired data were analyzed by Student's t-test. Data were analyzed using GraphPad Prism version 5.0 software (GraphPad Software, Inc., La Jolla, CA, USA). P $<0.05$ was considered to indicate a statistically significant difference.

\section{Results}

Analysis of the efficacy of isoflurane on pain remission and biochemical indexes in patients with hepatic carcinoma. In order to analyze the anesthetic effects of isoflurane, 156 patients with hepatic carcinoma were recruited, who had undergone tumor resection following pretreatment with isoflurane. As presented in Fig. 1A, pretreatment with isoflurane significantly attenuated pain in patients following tumor resection compared with in patients pretreated with propofol. Heart rate and mean blood pressure of patients were recorded from baseline to the 24-h anesthesia (24 h; Fig. 1B and C). Pretreatment with isoflurane reduced heart rate and mean arterial blood pressure in patients that underwent tumor resection. Measurement of biochemical indexes indicated that isoflurane pretreatment decreased creatinine and blood urea nitrogen levels in patients prior to anesthesia and at $24 \mathrm{~h}$ after anesthesia (Fig. 1D and E). Taken together, these findings suggested that pretreatment with isoflurane may efficiently attenuate pain remission for patients undergoing tumor resection.

Effects of isoflurane on proliferation, growth, migration and invasion of hepatic carcinoma cells. The present study investigated the efficacy of pretreatment of isoflurane on hepatic tumor cells. The results demonstrated that isoflurane significantly inhibited growth of hepatic carcinoma cells isolated from patients with cancer that had undergone tumor resection compared with propofol (Fig. 2A). Viability of hepatic carcinoma cells was also decreased following treatment with 
A
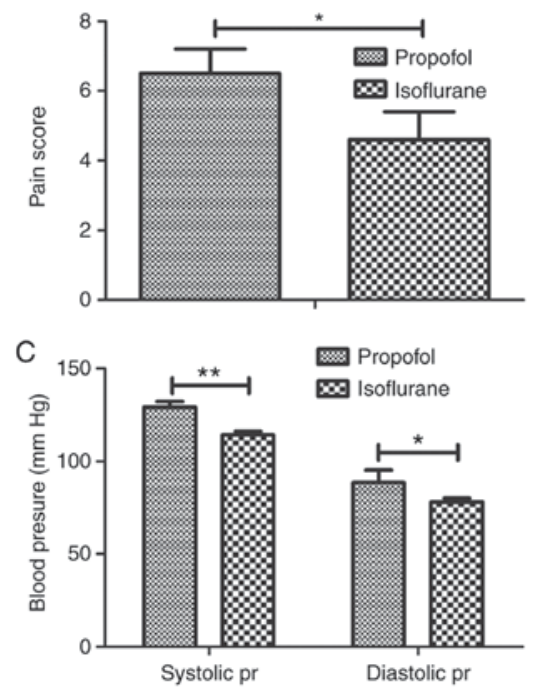

E

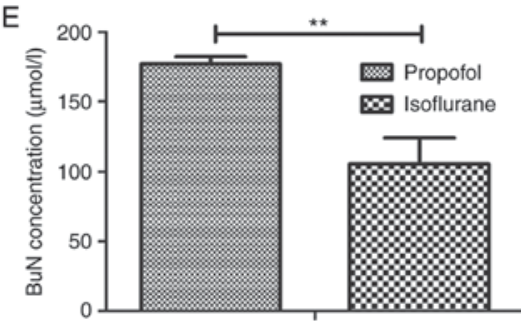

B

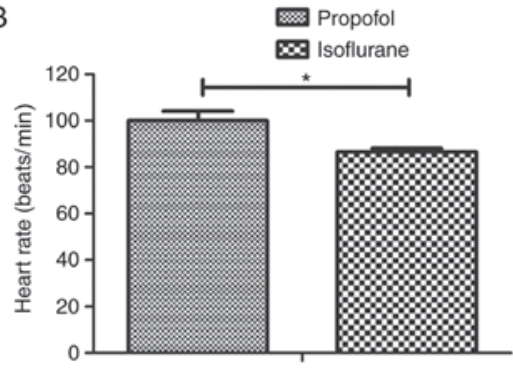

D

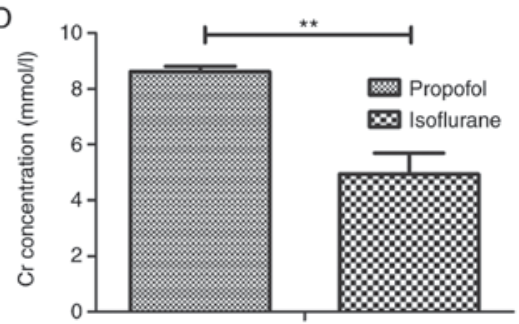

Figure 1. Effects of isoflurane on pain remission and biochemical indexes in patients with hepatic carcinoma. (A) Pain remission, (B) heart rate and (C) mean blood pressure of patients that underwent tumor resection following pretreatment with isoflurane. (D and $\mathrm{E}$ ) $\mathrm{Cr}$ and $\mathrm{BuN}$ levels of patients during the perioperative period. Data are presented as the mean \pm standard error of the mean of three independent experiments. $\mathrm{P}<0.05,{ }^{* *} \mathrm{P}<0.01$ vs. the control group. BuN, blood urea nitrogen; $\mathrm{Cr}$, creatinine.

A

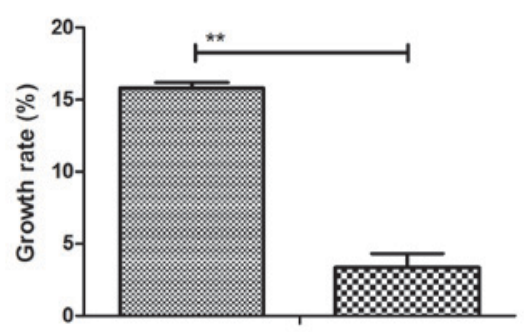

C
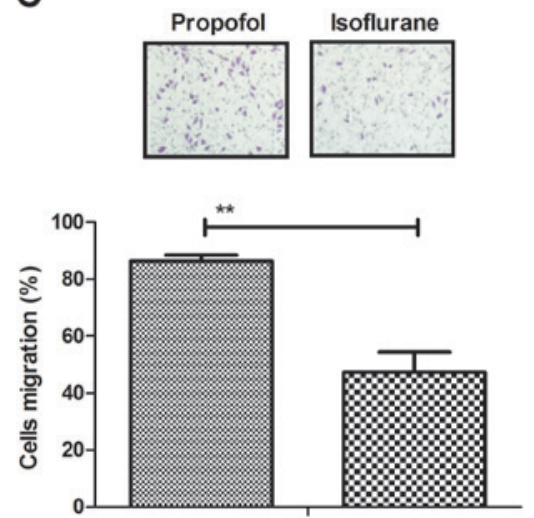

B

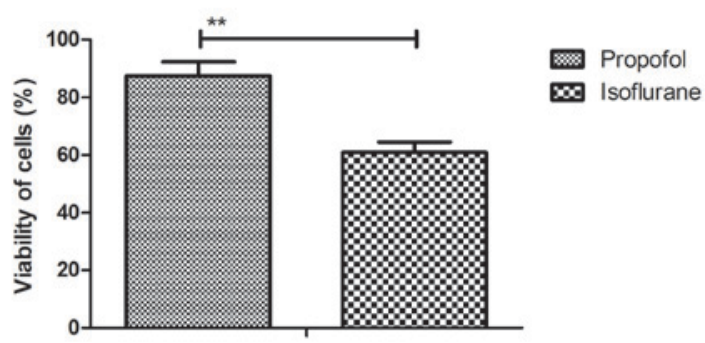

D

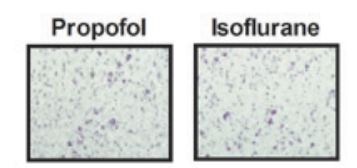

Propofol

$\infty$ Isoflurane

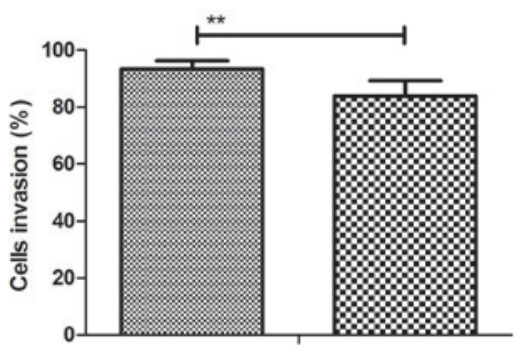

Propofol

$\infty$ Isoflurane

Figure 2. Effects of isoflurane on growth and aggressiveness of hepatic carcinoma cells. (A) Growth, (B) viability, (C) migration and (D) invasion of hepatic carcinoma cells from patients that underwent tumor resection following pretreatment with isoflurane (magnification, $\mathrm{x} 40$ ). Data are presented as the mean \pm standard error of the mean of three independent experiments. ${ }^{* *} \mathrm{P}<0.01$ vs. the control group. 
A
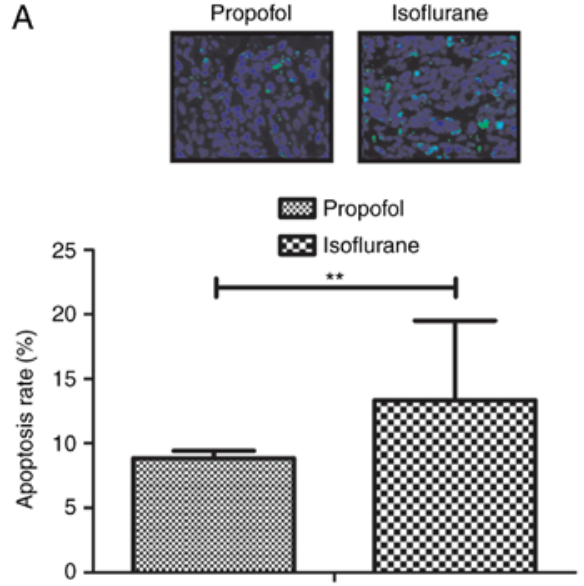

C

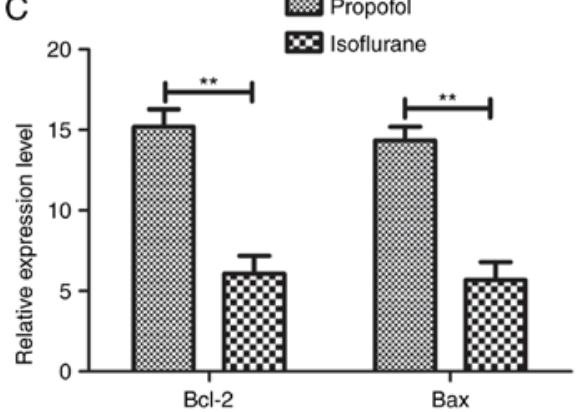

B

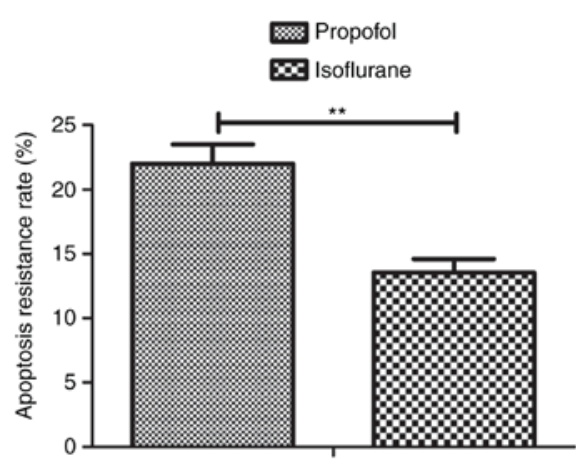

D

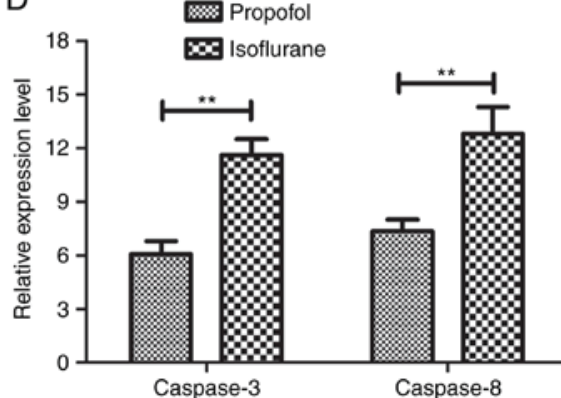

Figure 3. Effects of isoflurane on apoptosis of hepatic carcinoma cells isolated from patients with cancer. (A) Apoptosis of hepatic carcinoma cells from patients that underwent tumor resection following pretreatment with isoflurane (magnification, x40). (B) Apoptotic resistance of hepatic carcinoma cells treated with the anticancer chemotherapeutic agent Taxol. Expression levels of (C) Bcl-2 and Bax, and (D) caspase-3 and caspase-8 in hepatic carcinoma cells from patients that underwent tumor resection following pretreatment with isoflurane. Data are presented as the mean \pm standard error of the mean of three independent experiments. ${ }^{* *} \mathrm{P}<0.01$ vs. the control group. Bax, Bcl-2-associated $\mathrm{X}$ protein; Bcl-2, B cell lymphoma-2.

isoflurane compared with propofol (Fig. 2B). The results of migration and invasion assays demonstrated that the metastatic potential of hepatic carcinoma cells was reduced following isoflurane pretreatment compared with propofol (Fig. 2C and D). These observations suggested that isoflurane may inhibit growth, migration and invasion of hepatic carcinoma cells.

Effects of isoflurane on apoptosis and the expression levels of apoptotic genes in hepatic carcinoma cells. In order to investigate the anti-apoptotic effects of isoflurane on hepatic carcinoma cells, the apoptosis and survival rate of tumor cells isolated from patients were analyzed. As presented in Fig. 3A, isoflurane pretreatment increased the apoptosis of hepatic carcinoma cells. In addition, the apoptotic rate of hepatic carcinoma cells was increased in response to the anticancer chemotherapeutic agent Taxol, as determined by TUNEL assay (Fig. 3B). In addition, the expression levels of Bcl-2, Bax, caspase-3 and caspase- 8 were detected in hepatic carcinoma cells. Data demonstrated that the mRNA expression levels of Bcl-2 and Bax were downregulated in hepatic carcinoma cells following isoflurane treatment compared with control (Fig. 3C) Furthermore, the mRNA expression levels of caspase- 3 and caspase- 8 were upregulated in hepatic carcinoma cells following treatment with isoflurane compared with control (Fig. 3D). Collectively, these results indicated that isoflurane may decrease the survival rate and promote the apoptosis of hepatic carcinoma cells isolated from patients with hepatic carcinoma.

Isoflurane regulates aggressiveness of hepatic carcinoma cells via the PI3K/AKT signaling pathway. To investigate the molecular mechanism underlying isoflurane-mediated inhibition of aggressiveness of hepatic carcinoma cells, the PI3K/AKT signaling pathway was analyzed in hepatic carcinoma cells. The results demonstrated that the expression levels of PI3K and AKT were decreased in isoflurane-treated hepatic carcinoma cells compared with in propofol-treated cells (Fig. 4A). In addition, phosphorylation levels of AKT were downregulated in hepatic carcinoma cells following pretreatment with isoflurane compared with propofol (Fig. 4B). Furthermore, treatment with PI3KIR abolished isoflurane-induced apoptosis of hepatic carcinoma cells compared with propofol (Fig. 4C). Furthermore, PI3KIR treatment abolished Taxol-inhibited survival of hepatic carcinoma cells compared with propofol (Fig. 4D). Taken together, these results suggested that isoflurane may significantly regulate growth and apoptosis of hepatic carcinoma cells via the PI3K/AKT signaling pathway.

Isoflurane inhibits migration and invasion via the $P I 3 K / A K T$-mediated $N F-\kappa B$ signaling pathway. The present study further analyzed the expression levels of inflammatory factors and $\mathrm{NF}-\kappa \mathrm{B}$ in hepatic carcinoma cells. Clinical data 
A
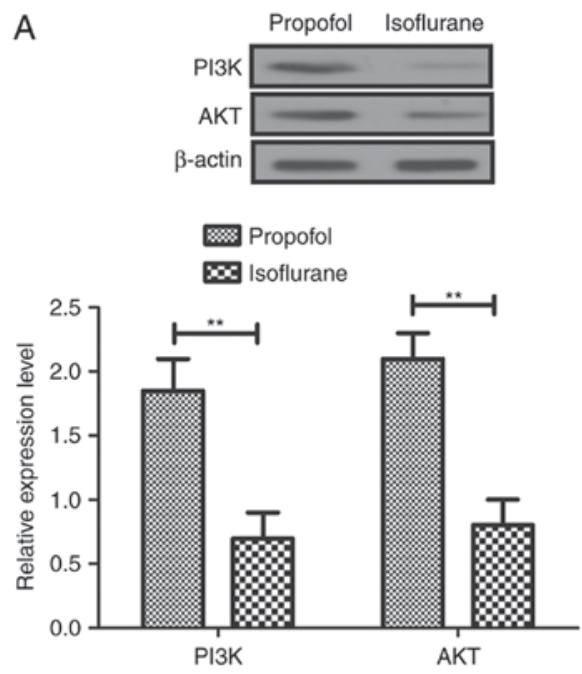

C
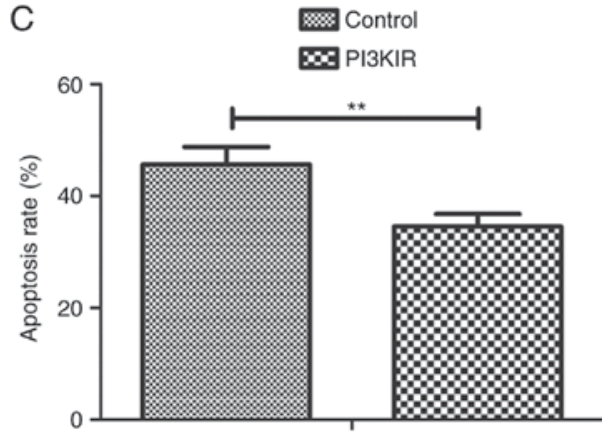

B
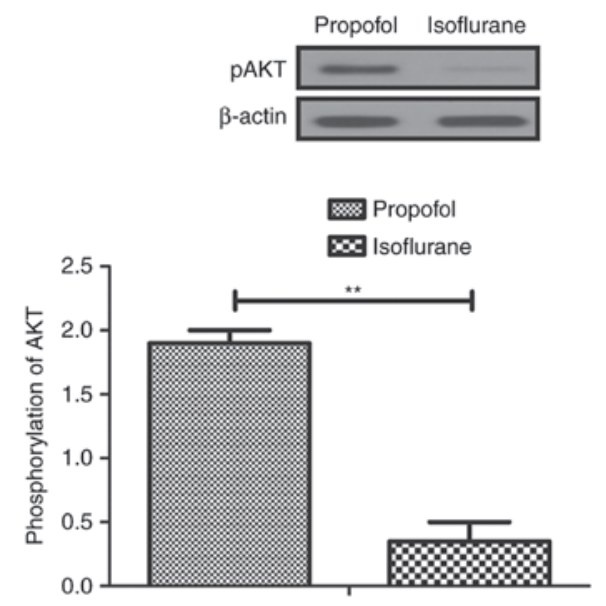

D

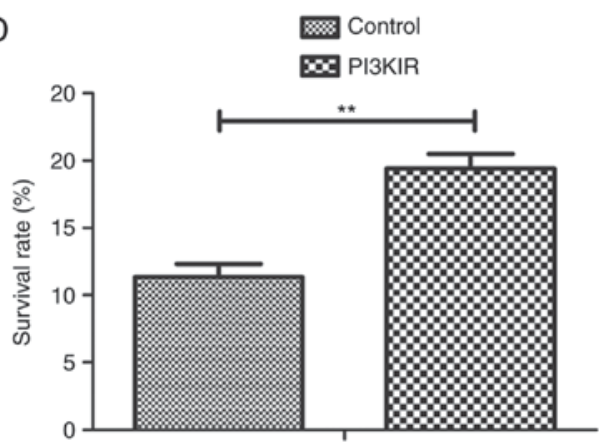

Figure 4. Isoflurane inhibits aggressiveness of hepatic carcinoma cells via the PI3K/AKT signaling pathway. (A) Expression levels of PI3K and AKT in isoflurane-treated hepatic carcinoma cells. (B) Phosphorylation levels of AKT in isoflurane-treated hepatic carcinoma cells. (C) Effects of PI3KIR on isoflurane-promoted apoptosis of hepatic carcinoma cells. Control, non-treated cells. (D) Effects of PI3KIR on survival of hepatic carcinoma cells. Control, non-treated cells. Data are presented as the mean \pm standard error of the mean of three independent experiments. ${ }^{* *} \mathrm{P}<0.01$ vs. the control group. AKT, protein kinase B; pAKT, phosphorylated-AKT; PI3K, phosphoinositide 3-kinase; PI3KIR, PI3K inhibitor.

revealed that $\mathrm{NF}-\kappa \mathrm{B}$ activity was downregulated in hepatic carcinoma cells isolated from patients that underwent isoflurane pretreatment compared with propofol (Fig. 5A). NF- $\kappa \mathrm{B}$ (p65, IKK- $\beta$ and $\mathrm{I} \kappa \mathrm{B} \alpha$ ) expression levels were also downregulated in hepatic carcinoma cells isolated from clinical patients with isoflurane pretreatment compared with propofol (Fig. 5B). In addition, PI3KIR downregulated $\mathrm{NF}-\kappa \mathrm{B}$ activity in hepatic carcinoma cells in vitro. PI3KIR also suppressed isoflurane-inhibited migration and invasion of hepatic carcinoma cells in vitro (Fig. 5D). Taken together, these results suggested that isoflurane may markedly inhibit migration and invasion via the PI3K/AKT-mediated $\mathrm{NF}-\kappa \mathrm{B}$ signaling pathway.

Pharmacodynamics of isoflurane in patients with hepatic carcinoma during the perioperative period. Inflammatory factor levels and pharmacodynamics of isoflurane were investigated in patients with hepatic carcinoma during the perioperative period. The expression levels of the inflammatory factors, TNF- $\alpha$ and IL-2, were upregulated in the serum of patients with hepatic carcinoma pretreated with isoflurane during the perioperative period (Fig. 6A and B). Isoflurane was rapidly absorbed at a clinical dose $(10 \mathrm{mg} / \mathrm{kg})$ within $30 \mathrm{~min}$. In addition, serum concentrations of isoflurane reached a maximum 45 min after injection (Fig. 6C). Furthermore, Cmax concentrations of isoflurane $(5-25 \mathrm{mg} / \mathrm{kg}$ ) increased linearly with increasing dose (Fig. 6D). There was no drug accumulation after patients received $10 \mathrm{mg} / \mathrm{kg}$ body weight and it was observed that $\mathrm{Cmax}$ values were at a steady state following tumor resection. Collectively, these results suggested that isoflurane pretreatment can be preserved at an efficient concentration and may increase the expression levels of TNF- $\alpha$ and IL-2 in patients with hepatic carcinoma during the perioperative period.

\section{Discussion}

Previous studies have indicated that hepatic carcinoma is associated with genetically complex, multifactorial and heterogeneous tumors $(24,25)$. Although various novel cancer therapeutic strategies have been proposed and have presented potential curative effects for the treatment of patients with hepatic carcinoma, tumor resection is still the most common treatment $(26,27)$. In order to attenuate the pain of patients during tumor resection, anesthesia is used. In the present study, the anesthetic effects of isoflurane were investigated on patients with hepatic carcinoma during the perioperative period. In addition, the biological effects of isoflurane on hepatic carcinoma were determined in patients with hepatic carcinoma who had undergone tumor resection. The molecular mechanism underlying isoflurane-induced apoptosis of hepatic carcinoma cells isolated from patients with hepatic carcinoma 


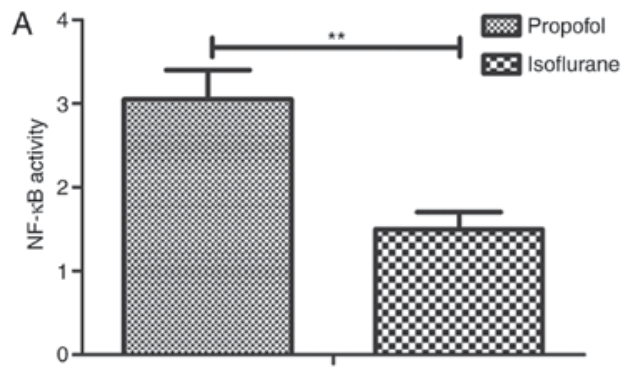

B

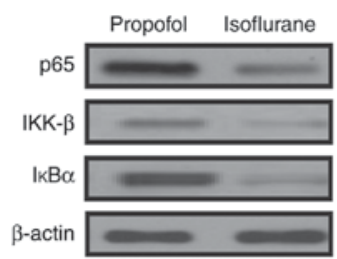

C
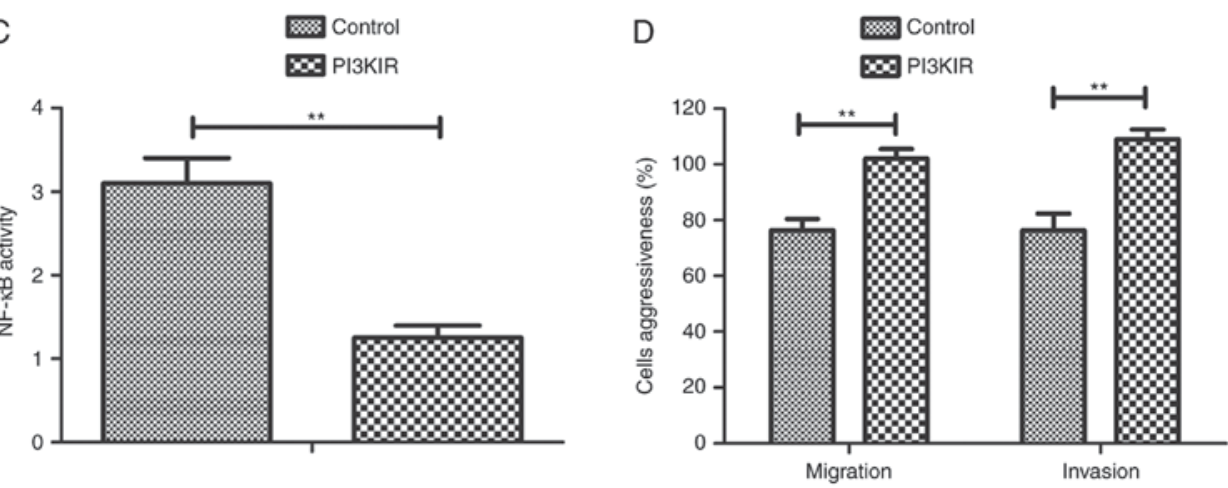

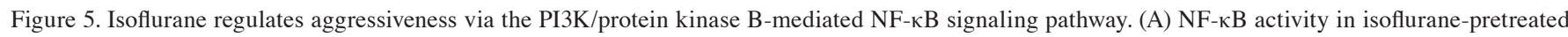
hepatic carcinoma cells. (B) Expression levels of p65, IKK- $\beta$ and IкB $\alpha$ in isoflurane-pretreated hepatic carcinoma cells. (C) Effects of PI3KIR on NF- $\kappa B$ activity in hepatic carcinoma cells. (D) Effects of PI3KIR on migration and invasion of hepatic carcinoma cells. Control, non-treated cells. Data are presented

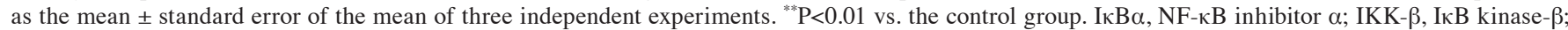
NF-kB, nuclear factor-kB; PI3K, phosphoinositide 3-kinase; PI3KIR, PI3K inhibitor.

A
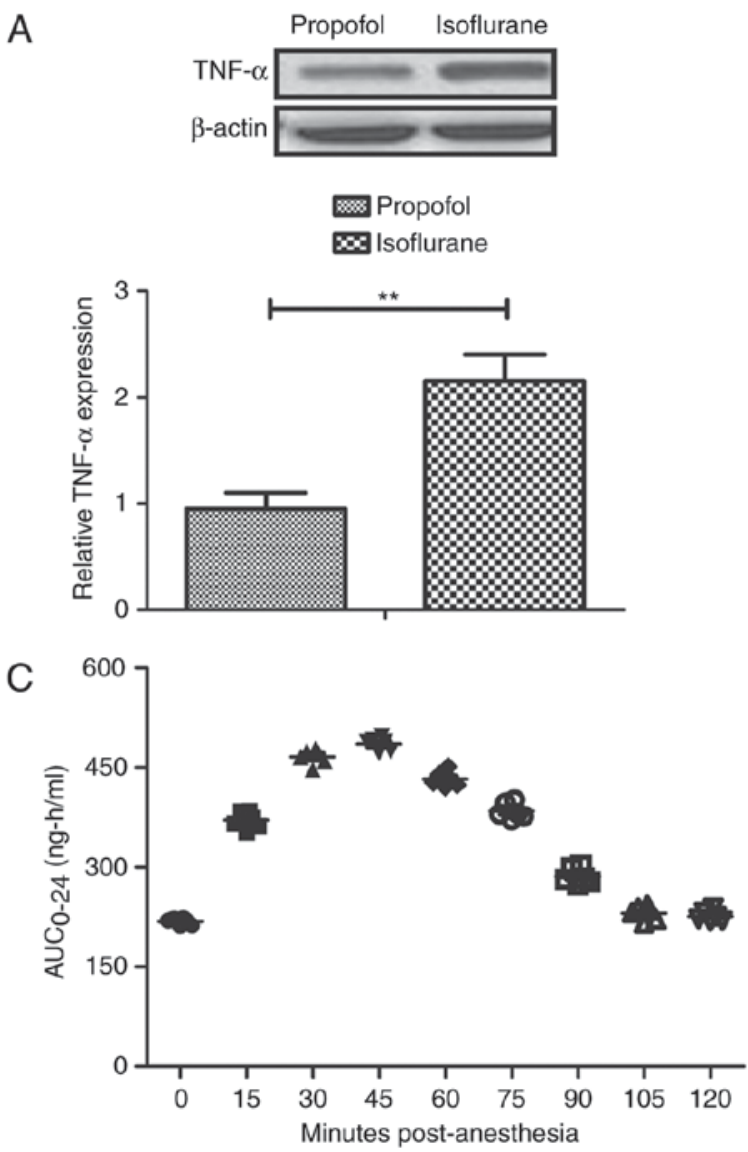

B
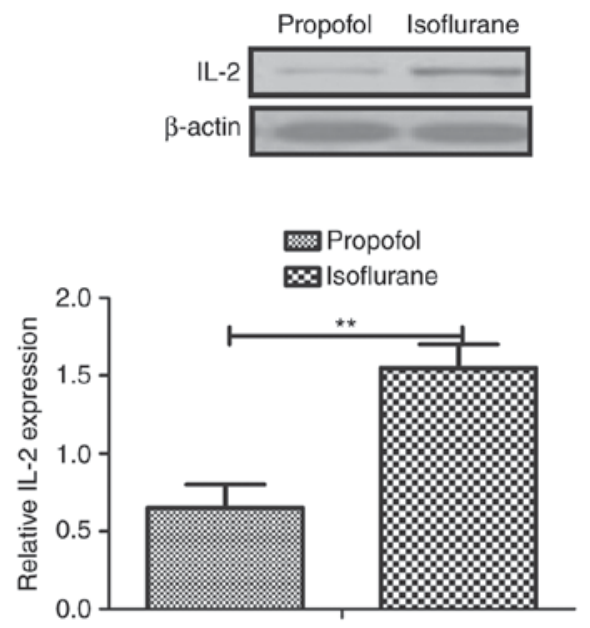

D

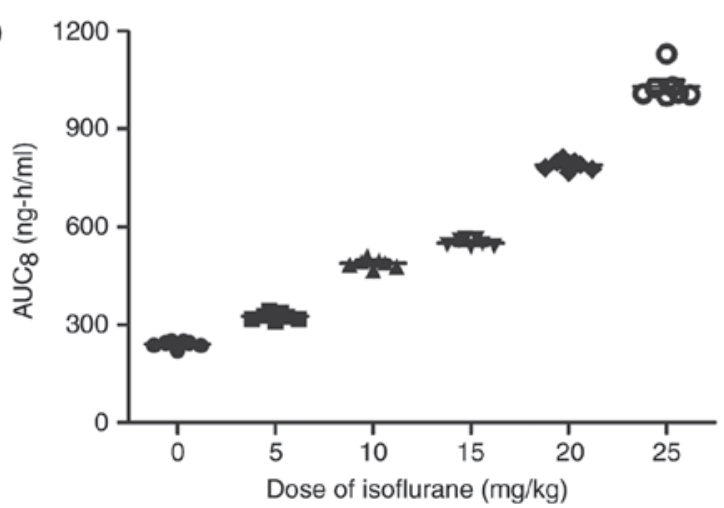

Figure 6. Pharmacodynamics of isoflurane in patients with hepatic carcinoma during the perioperative period. Expression levels of (A) TNF- $\alpha$ and (B) IL-2 in patients that underwent tumor resection following pretreatment with isoflurane. (C) Serum concentration of isoflurane in patients with hepatic carcinoma that underwent tumor resection following pretreatment with isoflurane. (D) Cmax concentrations of isoflurane (0-0.40 mg/kg) in patients with hepatic carcinoma that underwent tumor resection following pretreatment with isoflurane. Data are presented as the mean \pm standard error of the mean of three independent experiments. ${ }^{* *} \mathrm{P}<0.01$ vs. the control group. IL-2, interleukin-2; TNF- $\alpha$, tumor necrosis factor- $\alpha$. 
following surgery was also analyzed. The results indicated that isoflurane not only significantly attenuated postoperative pain, but also inhibited hepatic carcinoma growth and aggressiveness, and promoted apoptosis via the PI3K/AKT-mediated $\mathrm{NF}-\kappa \mathrm{B}$ signaling pathway.

Clinically, isoflurane is one of the most commonly used volatile anesthetic agents, which is used extensively in surgical procedures. However, the role of isoflurane in tumor suppression is seldom reported. In the present study, the clinical outcomes suggested that isoflurane may exert inhibitory effects on hepatic carcinoma cells. A previous study indicated that isoflurane can increase the expression levels of the proinflammatory cytokine IL-6 in serum from patients with neuroglioma, resulting in anticancer potential via the NF- $\mathrm{NB}$ signaling pathway. In addition, isoflurane suppresses prostate cancer cell malignancy via modulation of the hypoxia-inducible factor- $1 \alpha$ signaling pathway to regulate cancer recurrence (28). However, Luo et al (29) concluded that isoflurane can promote the malignant potential of ovarian cancer cells through the upregulation of markers associated with the cell cycle, growth, aggressiveness and angiogenesis. Furthermore, isoflurane has the potential to induce cancer cell apoptosis and inhibit apoptotic resistance (30). The results of the present study confirmed that isoflurane serves an inhibitory role in the growth, migration and invasion of hepatic carcinoma cells. In addition, it was suggested that isoflurane regulates aggressiveness of hepatic carcinoma cells via the PI3K/AKT-mediated NF- $\kappa$ B signaling pathway.

Previous studies have reported the association between the PI3K/AKT signaling pathway and progression of human cancer (31-33). Kang et al (34) suggested that the expression of proteins associated with the PI3K/AKT pathway may be considered indictors of the hepatic-metastasis risk of colorectal cancer. In addition, the effects of interferon- $\alpha$ on hepatic cancer via the PI3K/AKT signaling pathway have been identified and clearly elaborated in a previous mechanistic study (35). Furthermore, PI3K/AKT-mediated cancer cell growth and aggression via the $\mathrm{NF}-\kappa \mathrm{B}$ signaling pathway has been investigated in breast and gastric cancer cells $(36,37)$. Li et al (38) also analyzed the association between invasion of cancer cells and the PI3K/AKT/NF- $\mathrm{B}$ signaling pathway. In the present study, the effects of isoflurane were investigated on the PI3K/AKT and NF- $\mathrm{KB}$ signaling pathways. The results indicated that isoflurane inhibited growth and aggressiveness of hepatic carcinoma cells through downregulation of $\mathrm{PI} 3 \mathrm{~K} / \mathrm{AKT}$-induced NF- $\mathrm{B}$ signaling pathways. These findings provide novel evidence and a potential molecular mechanism underlying the anticancer effects of isoflurane.

Notably, the present findings demonstrated that apoptosis of hepatic carcinoma cells was enhanced by isoflurane. Clinically, apoptosis of tumors cells serves a crucial role in tumor suppression and the treatment of human cancer $(39,40)$. The present study demonstrated that the mRNA expression levels of caspase- 3 and caspase- 8 were upregulated in hepatic carcinoma cells treated with isoflurane. Caspase- 3 and caspase- 8 upregulation contributes to apoptosis of hepatic carcinoma cells, and decreases apoptotic resistance $(41,42)$. In addition, a previous study suggested that apoptosis and cell proliferation are correlated with Bcl-2 expression in human hepatocellular carcinoma (43). Bax-induced apoptosis, has been investigated in numerous tumor cells (44). In the present study, isoflurane was revealed to reduce apoptotic resistance via the upregulation of caspase- 3 and caspase- 8 expression, and the downregulation of Bcl-2 and Bax expression. The downregulation of Bax induced by isoflurane should be investigated in future studies.

In conclusion, the present study identified the benefits of isoflurane pretreatment for patients with hepatic carcinoma. This study indicated that the inhibitory effects of isoflurane on hepatic cancer aggressiveness may be mediated by regulation of the PI3K/AKT-induced $\mathrm{NF}-\kappa \mathrm{B}$ signaling pathway. In addition, the results suggested that isoflurane may suppress apoptotic resistance via activation of caspase- 3 and caspase- 8 , and suppression of Bcl-2 and Bax. These findings indicated that isoflurane may be regarded as a preferable anesthetic and additional antitumor agent for the clinical treatment of patients with hepatic carcinoma.

\section{Acknowledgements}

Not applicable.

\section{Funding}

No funding was received.

\section{Availability of data and materials}

The analyzed data sets generated during the study are available from the corresponding author on reasonable request.

\section{Authors' contributions}

QGL designed the research. JH, JLH and HMJ performed the research and analyzed data. JH and QGL wrote the manuscript. All authors read and approved the final manuscript.

\section{Ethics approval and consent to participate}

The present study was directed according to the Guide for the Care and Use of Clinical Investigation of Anesthesiology of Linyi Cancer Hospital (Linyi, China). The present study was approved by the ethics committee of Linyi Cancer Hospital.

\section{Consent for publication}

All patients provided written informed consent.

\section{Competing interests}

The authors declare that they have no competing interests.

\section{References}

1. Kao HK, Guo LF, Cheng MH, Chen IH, Liao CT, Fang KH, Yu JS and Chang KP: Predicting postoperative morbidity and mortality by model for endstage liver disease score for patients with head and neck cancer and liver cirrhosis. Head Neck 33: 529-534, 2011.

2. Menon KV, Hakeem AR and Heaton ND: Review article: Liver transplantation for hepatocellular carcinoma-a critical appraisal of the current worldwide listing criteria. Aliment Pharmacol Ther 40: 893-902, 2014. 
3. Shariff MI, Cox IJ, Gomaa AI, Khan SA, Gedroyc W and Taylor-Robinson SD: Hepatocellular carcinoma: Current trends in worldwide epidemiology, risk factors, diagnosis and therapeutics. Expert Rev Gastroenterol Hepatol 3: 353-367, 2009.

4. Philip-Ephraim EE, Eyong KI, Williams UE and Ephraim RP: The role of radiotherapy and chemotherapy in the treatment of primary adult high grade gliomas: Assessment of patients for these treatment approaches and the common immediate side effects. ISRN Oncol 2012: 902178, 2012.

5. Bai P,Zhang R, Li XG, Ma SK, Wu LY and Zhang WH: Efficiency and side effects of concurrent radiotherapy and chemotherapy for advanced cervical cancers. Zhonghua Zhong Liu Za Zhi 29: 467-469, 2007 (In Chinese).

6. Huang YH, Wu JC, Chen SC, Chen $\mathrm{CH}$, Chiang JH, Huo TI, Lee PC, Chang FY and Lee SD: Survival benefit of transcatheter arterial chemoembolization in patients with hepatocellular carcinoma larger than $10 \mathrm{~cm}$ in diameter. Aliment Pharmacol Ther 23 $129-135,2006$

7. Joseph JD, Peng Y, Mak DO, Cheung KH, Vais H, Foskett JK and Wei H: General anesthetic isoflurane modulates inosito 1,4,5-trisphosphate receptor calcium channel opening. Anesthesiology 121: 528-537, 2014.

8. Yu C, Luo YL, Xiao SS, Zhang Q and Chen SL: Influence of propofol and isoflurane on cytokines response to cancer surgery during perioperative period. Hua Xi Kou Qiang Yi Xue Za Zhi 25: 554-556, 2007 (In Chinese).

9. Jiang $\mathbf{J}$ and Jiang $\mathrm{H}$ : Effect of the inhaled anesthetics isoflurane, sevoflurane and desflurane on the neuropathogenesis of Alzheimer's disease (review). Mol Med Rep 12: 3-12, 2015.

10. Liu TC: Influence of propofol, isoflurane and enflurance on levels of serum interleukin- 8 and interleukin-10 in cancer patients Asian Pac J Cancer Prev 15: 6703-6707, 2014.

11. Yang H, Deng J, Jiang Y, Chen J, Zeng X, He Z, Jiang X, Li Z and Jiang C: Emulsified isoflurane treatment inhibits the cell cycle and respiration of human bronchial epithelial 16HBE cells in a p53-independent manner. Mol Med Rep 14: 349-354, 2016.

12. Miura Y, Kamiya K, Kanazawa K, Okada M, Nakane M, Kumasaka A and Kawamae K: Superior recovery profiles of propofol-based regimen as compared to isoflurane-based regimen in patients undergoing craniotomy for primary brain tumor excision: A retrospective study. J Anesth 26: 721-727, 2012.

13. Lim KH and Counter CM: Reduction in the requirement of oncogenic Ras signaling to activation of PI3K/AKT pathway during tumor maintenance. Cancer cell 8: 381-392, 2005.

14. Shi LX, Wang JH and Shi XD: PI3K/AKT/mTOR Pathway and Pediatric T acute lymphoblastic leukemia-review. Zhongguo Shi Yan Xue Ye Xue Za Zhi 24: 1269-1274, 2016 (In Chinese).

15. Dey JH, Bianchi F, Voshol J, Bonenfant D, Oakeley EJ and Hynes NE: Targeting fibroblast growth factor receptors blocks PI3K/AKT signaling, induces apoptosis, and impairs mammary tumor outgrow th and metastasis. Cancer Res 70: 4151-4162, 2010

16. Wang CM, Cai XL and Wen QP: Astaxanthin reduces isoflurane-induced neuroapoptosis via the PI3K/Akt pathway. Mol Med Rep 13: 4073-4078, 2016.

17. Zhao K, Song X, Huang Y, Yao J, Zhou M, Li Z, You Q, Guo Q and $\mathrm{Lu}$ N: Wogonin inhibits LPS-induced tumor angiogenesis via suppressing PI3K/Akt/NF-кB signaling. Eur J Pharmacol 737 : 57-69, 2014.

18. Miao X and Zhao Y: ST6GalNAcII mediates tumor invasion through PI3K/Akt/NF- $\kappa$ B signaling pathway in follicular thyroid carcinoma. Oncol Rep 35: 2131-2140, 2016.

19. Al-Sobayil FA and Omer OH: Serum biochemical values of adult ostriches (Struthio camelus) anesthetized with xylazine, ketamine, and isoflurane. J Avian Med Surg 25: 97-101, 2011.

20. Livak KJ and Schmittgen TD: Analysis of relative gene expression data using real-time quantitative PCR and the 2(-Delta Delta C(T)) method. Methods 25: 402-408, 2001.

21. Nilsson U and Idvall E: Pain assessments in day surgery patients. J Clin Nurs 19: 2942-2943, 2010

22. Zheng N, Wei X, Zhang D, Chai W, Che M, Wang J and Du B: Hepatic resection or transarterial chemoembolization for hepatocellular carcinoma with portal vein tumor thrombus. Medicine (Baltimore) 95: e3959, 2016.

23. Jia YS, Hu XQ, Gabriella H, Qin LJ and Meggyeshazi N Antitumor activity of tenacissoside $\mathrm{H}$ on esophageal cancer through arresting cell cycle and regulating PI3K/Akt-NF- $\kappa \mathrm{B}$ transduction cascade. Evid Based Complement Alternat Med 2015: 464937, 2015

24. Simonetti RG, Cammà C, Fiorello F, Politi F, D'Amico G and Pagliaro L: Hepatocellular carcinoma. A worldwide problem and the major risk factors. Dig Dis Sci 36: 962-972, 1991.
25. Zidan A, Scheuerlein H, Schüle S, Settmacher U and Rauchfuss F Epidemiological pattern of hepatitis B and hepatitis C as etiological agents for hepatocellular carcinoma in iran and worldwide. Hepat Mon 12: e6894, 2012.

26. Marabelle A and Gray J: Tumor-targeted and immune-targeted monoclonal antibodies: Going from passive to active immunotherapy. Pediatr Blood Cancer 62: 1317-1325, 2015.

27. Nishimura Y, Tomita Y, Yuno A, Yoshitake Y and Shinohara M: Cancer immunotherapy using novel tumor-associated antigenic peptides identified by genome-wide cDNA microarray analyses Cancer Sci 106: 505-511, 2015.

28. Huang H, Benzonana LL, Zhao H, Watts HR, Perry NJ, Bevan C, Brown R and Ma D: Prostate cancer cell malignancy via modulation of HIF-1 $\alpha$ pathway with isoflurane and propofol alone and in combination. Br J Cancer 111: 1338-1349, 2014.

29. Luo X, Zhao H, Hennah L, Ning J, Liu J, Tu H and Ma D: Impact of isoflurane on malignant capability of ovarian cancer in vitro. Br J Anaesth 114: 831-839, 2015

30. Zhang Y, Dong Y, Wu X, Lu Y, Xu Z, Knapp A, Yue Y, $\mathrm{Xu} \mathrm{T}$ and $\mathrm{Xie} \mathrm{Z}$ : The mitochondrial pathway of anesthetic isoflurane-induced apoptosis. J Biol Chem 285: 4025-4037, 2010.

31. Mu GG, Zhang LL, Li HY, Liao Y and Yu HG: Thymoquinone pretreatment overcomes the insensitivity and potentiates the antitumor effect of gemcitabine through abrogation of Notch1, $\mathrm{PI} 3 \mathrm{~K} / \mathrm{Akt} / \mathrm{mTOR}$ regulated signaling pathways in pancreatic cancer. Dig Dis Sci 60: 1067-1080, 2015.

32. Coco S, Truini A, Alama A, Dal Bello MG, Venè R, Garuti A, Carminati E, Rijavec E, Genova C, Barletta G, et al: Afatinib resistance in non-small cell lung cancer involves the PI3K/AKT and MAPK/ERK signalling pathways and epithelial-to-mesenchymal transition. Targeted Oncol 10: 393-404, 2015.

33. Yang Y, Zhang J, Zhu Y, Zhang Z, Sun H and Feng Y: Follicle-stimulating hormone induced epithelial-mesenchymal transition of epithelial ovarian cancer cells through follicle-stimulating hormone receptor PI3K/Akt-Snail signaling pathway. Int J Gynecol Cancer 24: 1564-1574, 2014.

34. Kang B, Hao C, Wang H, Zhang J, Xing R, Shao J, Li W, $\mathrm{Xu} \mathrm{N}, \mathrm{Lu} \mathrm{Y}$ and Liu S: Evaluation of hepatic-metastasis risk of colorectal cancer upon the protein signature of PI3K/AKT pathway. J Proteome Res 7: 3507-3515, 2008

35. Yan L and Shi G: Effect of IFN- $\alpha$ on hepatic cancer SMCC-7721 cell via PI3K/Akt signaling pathway and related mechanism research. Zhonghua Yi Xue Za Zhi 95: 2960-2963, 2015 (In Chinese).

36. Sha M, Ye J, Zhang LX, Luan ZY, Chen YB and Huang JX: Celastrol induces apoptosis of gastric cancer cells by miR-21 inhibiting PI3K/Akt-NF-кB signaling pathway. Pharmacology 93: 39-46, 2014.

37. Rabi T, Huwiler A and Zangemeister-Wittke U: AMR-Me inhibits PI3K/Akt signaling in hormone-dependent MCF-7 breast cancer cells and inactivates $\mathrm{NF}-\kappa \mathrm{B}$ in hormone-independent MDA-MB-231 cells. Mol Carcinog 53: 578-588, 2014

38. Li C, Li F, Zhao K, Yao J, Cheng Y, Zhao L, Li Z, Lu N and Guo Q: LFG-500 inhibits the invasion of cancer cells via down-regulation of PI3K/AKT/NF- $\kappa$ B signaling pathway. PloS One 9: e91332, 2014.

39. Dastjerdi MN, Babazadeh Z, Rabbani M, Gharagozloo M, Esmaeili A and Narimani M: Effects of disulfiram on apoptosis in PANC-1 human pancreatic cancer cell line. Res Pharm Sci 9: 287-294, 2014.

40. Tengku Din TA, Seeni A, Khairi WN, Shamsuddin S and Jaafar H: Effects of rapamycin on cell apoptosis in MCF-7 human breast cancer cells. Asian Pac J Cancer Prev 15: 10659-10663, 2014.

41. Russe OQ, Möser CV, Kynast KL, King TS, Olbrich K, Grösch S, Geisslinger $G$ and Niederberger E: LPS inhibits caspase 3-dependent apoptosis in RAW264.7 macrophages induced by the AMPK activator AICAR. Biochem Biophys Res Commun 447: 520-525, 2014

42. Mandal R, Raab M, Matthess Y, Becker S, Knecht R and Strebhardt K: Perk 1/2 inhibit Caspase-8 induced apoptosis in cancer cells by phosphorylating it in a cell cycle specific manner. Mol Oncol 8: 232-249, 2014.

43. EI-Emshaty HM, Saad EA, Toson EA, Abdel Malak CA and Gadelhak NA: Apoptosis and cell proliferation: Correlation with BCL-2 and P53 oncoprotein expression in human hepatocellular carcinoma. Hepatogastroenterology 61: 1393-1401, 2014.

44. Tsai CJ, Liu S, Hung CL, Jhong SR, Sung TC and Chiang YW: BAX-induced apoptosis can be initiated through a conformational selection mechanism. Structure 23: 139-148, 2015. 